\title{
Dose-dependent regulation of cell proliferation and collagen degradation by estradiol on ligamentum flavum
}

\author{
Mei-Hsiu Chen ${ }^{1}$, Chao-Kai Hu ${ }^{2,3}$, Pei-Ru Chen ${ }^{4}$, Yu-Shan Chen ${ }^{5}$, Jui-Sheng Sun ${ }^{6}$ and Ming-Hong Chen ${ }^{4,5,7^{*}}$
}

\begin{abstract}
Background: Estradiol plays an important role in the regulation of collagen metabolism. Deficiency of estradiol has been reported to be associated with the degeneration of many connective tissues. However, the association of estradiol and hypertrophy of the ligamentum flavum was seldom explored. Therefore, we studied the effects of estradiol on cultured cells from the ligamentum flavum.

Methods: Primary cultures of human ligamentum flavum cells obtained from surgical specimens of 14 patients undergoing spinal surgery were used to investigate the effect of estradiol on cell proliferation and the expression of collagen, elastin, and matrix metalloproteinases. Downstream pathways of estrogen receptor underlying the regulation of metalloproteinases were also investigated.

Results: In our study, we revealed the existence of estrogen receptors on both female and male ligamentum flavum cells with a gender difference. 17ß-estradiol increased early (24 hours) proliferation of ligamentum flavum cells in a dose dependent manner and the effect could not be seen when the cell density increased. Estradiol with a concentration of $10^{-9} \mathrm{M}$ decreased collagen levels and increased the expression of MMP-13. Adding an antagonist of PI3K downstream pathway could reverse the expression of MMP-13 caused by estradiol.
\end{abstract}

Conclusions: The results implied estradiol regulated the expression of MMP-13 via PI3K pathway and contributed to the homeostasis of extracellular matrix in the ligamentum flavum.

Keywords: Estradiol, Ligamentum flavum, Matrix metalloproteinases, Collagen, Elastin

\section{Background}

Lumbar spinal stenosis is one of the most common spinal disorders in the elderly patients [1]. Hypertrophy of the ligamentum flavum (LF) in combination with osteophyte formation of facet joints and degenerative spondylolisthesis can contribute to the development of lumbar spinal stenosis [2]. Although it is agreed that spinal mechanical stress accelerates the hypertrophy of ligamentum flavum which contributes to the development of spondylotic stenosis of the lumbar spine [3], the detailed underlying mechanism is not fully understood. A recent population-based cohort study in Japan revealed

\footnotetext{
* Correspondence: chen.minghong@gmail.com

${ }^{4}$ Department of Biomedical Engineering, Ming Chuan University, Taoyuan, Taiwan

${ }^{5}$ Department of Biomedical Engineering, National Yang-Ming University,

Taipei, Taiwan

Full list of author information is available at the end of the article
}

the prevalence of lumbar spinal stenosis for women was higher in increased age but showed only little difference in men with age greater than 70 years [4]. Matveeva et al also reported that lumbar stenosis in older female patients often involves more vertebral bodies than that in older male [5]. These evidences suggested that difference in genders plays a certain role in the pathogenesis of lumbar spinal stenosis. Therefore, we suspected that estradiol, as an important hormone during the aging processes in different genders, has a role in the development of degenerative spinal stenosis. It is also well recognized that estradiol deficiency is the major factor contributing to bone loss and osteoporotic vertebral fracture after menopause. However, previous studies showed that there is an inverse relation between osteoporosis and lumbar spondylotic stenosis in postmenopausal women [6]. Hence, we believed estradiol might have influences on 
the pathomechanisms of lumbar spondylotic stenosis through the matrix metabolism of spinal ligaments rather than its effects on vertebral bony structures. The ligamentum flavum, as a key spinal ligament, also named the yellow ligament because of its richness in yellow elastin. It contains $60 \%-70 \%$ of elastic fibers [7] and, between elastic fibers, there were small diameter collagen fibrils, which were linked with the proteoglycans [8]. Degenerative ligamentum flavum in lumbar stenosis showed decreased elasticity and increased fibrosis. The degree of fibrosis and the ligamentum flavum thickness had a positive correlation [9]. The increased collagen-toelastin ratio has also been considered as a sign of developing lumbar spinal stenosis in elder patients [10]. On the other hand, estradiol plays an important role in the regulation of collagen metabolism [11]. Deficiency of estradiol has been reported to be associated with collagen metabolism and the subsequent degeneration of skin, arteries, bone and intervertebral discs [11-13]. Previous studies also revealed that estradiol can increase the expression of elastin in rat Achilles tendon fibroblasts [14], rat prostates [15], human smooth muscles [16], and skin [17]. Estradiol can even stimulate the enzyme activity and accelerate the maturation of collagen and elastin in extracellular space in mice [18]. Contrarily, other reports suggest estradiol can interfere with elastin expression via TGF- $\beta$ signalling and result in improper assembly of elastic fibers [19]. However, the association of estradiol and matrix metabolism of the ligamentum flavum had seldom been explored. Furthermore, the extracellular matrix molecules can be degraded only by specific enzyme, particularly the various metalloproteinases (MMPs), which are the main players in the catabolism of collagen molecules. The MMPs can be divided into four groups [20] on the basis of substrate specificity (namely collagenase, gelatinase, stromelysins, and membrane-type MMPs). Among various MMPs, MMP-1 and MMP-13 can cleave intact interstitial collagen molecules. In addition, MMP-2 and MMP-9 can degrade denatured collagen molecules and basement membrane collagens. To understand the equilibrium between matrix degradation and synthesis in the aging and /or degenerative ligamentum flavum, it is important to evaluate the expression and activity of MMPs. In the present work, we investigated the effects of estradiol on cultured human ligamentum flavum cells by examining the presence of estradiol receptors, effects of estradiol on cell proliferation, regulation of collagen and elastin metabolisms, the relationship of matrix metalloproteinases (MMPs) with estradiol treatment and the signaling mechanisms underlying it. The benefits of estrogen replacement therapy in osteoporosis and related bone fracture have been well established. Through this study, the understandings of estradiol's effects on cell proliferation and matrix metabolism of the ligamentum flavum should provide more insights into the influences of estradiol on the pathophysiology of spondylotic lumbar stenosis during aging in women.

\section{Methods \\ Sample collection}

Surgical specimens of ligamentum flavum were obtained from 14 patients ( 8 female and 6 male, mean age was 58.8 , range from 45 to 78 years) undergoing spinal surgery under the diagnosis of lumbar spinal stenosis with or without spondylolisthesis, herniated intervertebral disc, and degenerative disc disease. Written informed consent for participation in this study was obtained from all participants. Two samples were used for immunohistochemistry and the rest of the samples were pooled for studies due to low cellularity and limited proliferation capacity of LF. All the study procedures received approval of the Ethic Committee of Taipei City Hospital (TCHIRB-980307-E).

\section{Culture of human LF cells}

The specimens were washed twice in phosphate-buffered saline (PBS) with penicillin-streptomycin, cut into small pieces (approximately $1.0 \mathrm{~mm} 3$ ), and placed in a $10 \mathrm{~cm}$ culture dish with $7 \mathrm{ml}$ of high glucose Dulbecco's Modified Eagle Medium (DMEM) with 10\% fetal bovine serum (FBS) and $100 \mathrm{IU} / \mathrm{mL}$ penicillin/streptomycin. Cultures were maintained at $37^{\circ} \mathrm{C}$ in a water-saturated atmosphere of $95 \%$ air and $5 \% \mathrm{CO}_{2}$. Cells under passaged 3-6 were used in the following experiments.

\section{Immunohistochemistry}

One male sample and one female sample were used separately to evaluate the presence of estrogen receptors on cells from both genders. Cells were collected by centrifuge and cytospin was used to make cells attach on the slides. Cells on the slides were fixed by $95 \%$ alcohol and stained with haematoxylin and estrogen receptor $\alpha$ and $\beta$. Antibodies for immunohistochemical staining of estrogen receptors were purchased from Thermo Fisher Scientific, CA, USA.

\section{Cell proliferation evaluated by 3-[4,5-dimethylthiazol]-2,5-} diphenylterazolium bromide (MTT) assay

Cell proliferation was measured using MTT cell proliferation assay kit (Sigma Co., St. Louis, MO, USA) at 1, 3 and 7 days. Briefly, cells $\left(3.0 \times 10^{5}\right.$ per well) were seeded in a 96-well plate and incubated in DMEM (100 $\mu$ l per well) with 10\% FBS overnight to allow cells to adhere to the plate. The medium was changed with fresh medium containing $17 \beta$-estradiol $\left(10^{-7}<10^{-10} \mathrm{M}\right)$ and $2 \%$ FBS every 48 hours. At scheduled time points for MTT assay, the culture medium was removed and the plate was washed twice with PBS. After adding $100 \mu \mathrm{l}$ of fresh 
culture medium with $10 \mu \mathrm{l}$ of the $12 \mathrm{mM}$ MTT stock solution, the plate was incubated at $37^{\circ} \mathrm{C}$ for 4 hours. The enzyme activity in viable cells would convert MTT to dark blue crystals of formazan. After discarding the medium with MTT solution and adding $50 \mu \mathrm{l}$ dimethylsulfoxide (DMSO) to each well with thorough pipetting, the dark blue crystals were dissolved and the colorless DMSO turned purple. The plate was placed in the Infinite 200 PRO multimode microplate reader (Tecan Group Ltd., Switzerland) to read the absorbance at $570 \mathrm{~nm}$.

\section{Total collagen in medium measured by Sircol collagen assay}

Cells $\left(3.0 \times 10^{5}\right.$ per well $)$ were seeded in a 6 -well plate and incubate in DMEM with 10\% FBS. Cells were allowed to adhere to the plate overnight, and then the medium was changed to DMEM ( $2 \mathrm{ml}$ per well) containing $17 \beta$-estradiol $\left(10^{-7}<10^{-9} \mathrm{M}\right)$ with $2 \%$ FBS. After 10 days, $200 \mu \mathrm{l}$ sample medium of each group was transfer to a $1.5 \mathrm{ml}$ centrifuge tube and mixed with $1.0 \mathrm{ml}$ Sircol Dye Reagent (Biocolor, Newtownabbey, Northern Ireland). The tubes were placed in a gentle mechanical shaker for 30 minutes and then centrifuged at 12,000 rpm for 10 minutes. The supernatant was discarded. The unbound dye was removed from the surface of the pellet and inner surface of the tube by rinsing with Acid-Salt Wash Reagent. The remaining pellets were mixed with $250 \mu \mathrm{l}$ of alkali reagent and $200 \mu \mathrm{l}$ of each sample was transferred to each well of a 96-well plate to measure the absorbance at $555 \mathrm{~nm}$.

\section{Total elastin in medium measured by FASTIN elastin assay}

Cells $\left(3.0 \times 10^{5}\right.$ per well $)$ were seeded in a 6 -well plate and incubate in DMEM with 10\% FBS. Cells were allowed to adhere to the plate overnight, and then the medium was changed to DMEM (2 $\mathrm{ml}$ per well) containing $17 \beta$-estradiol $\left(10^{-7}<10^{-9} \mathrm{M}\right)$ with $2 \%$ FBS. After 10 days, $100 \mu \mathrm{l}$ of sample medium in each group was transferred to a $1.5 \mathrm{ml}$ centrifuge tube and mixed well with equal volume of Elastin Precipitating Reagent (Biocolor, Newtownabbey, Northern Ireland) by vortexing. The tubes were centrifuged at $10,000 \mathrm{~g}$ for 10 minutes. The supernatant was removed and $1 \mathrm{ml}$ of dye reagent was added into each tube. After standing for 90 minutes, the tubes were centrifuged at $10,000 \mathrm{~g}$ for 10 minutes and unbound dye was drained off. $250 \mu \mathrm{l}$ of Dye Dissociation Reagent was added to each tube followed by vortexing to release the dye. The samples were then transferred to a 96-well plate to measure the absorbance at $513 \mathrm{~nm}$.

\section{RNA extraction}

Cells $\left(3.0 \times 10^{5}\right.$ per well) were seeded in a 6 -well plate and incubate in DMEM with 10\% FBS. After 24 hours, $17 \beta$-estradiol $\left(10^{-7}<10^{-9} \mathrm{M}\right)$ with vehicle, ICI 182780
(Fulvestrant; Sigma, USA), or LY-294002 (Sigma, USA) were added to the cells and incubated for 24 hours. After incubation, culture medium was discarded and each well was washed with PBS twice. Cells were lysed in a culture dish by adding $1 \mathrm{ml}$ TRIZOL reagent (Invitrogen Life Technologies, Carlsbad, CA, USA). The homogenized samples were incubated for 5 minutes at room temperature to permit complete dissociation of the nucleoprotein complex. Samples were then shook vigorously for 15 seconds after adding $0.2 \mathrm{ml}$ chloroform and centrifuged at $12,000 \mathrm{~g}$ for 10 minutes at $4^{\circ} \mathrm{C}$. The supernatant was removed. The RNA pellet was washed once with $75 \%$ ethanol and centrifuged at $7500 \mathrm{~g}$ for 5 minutes at $4^{\circ} \mathrm{C}$. RNA was air-dried for 5 minutes and dissolved in DEPC-treated $\mathrm{ddH}_{2} \mathrm{O}$.

\section{Reverse transcription}

$1 \mu \mathrm{l}$ oligo(dT), $1 \mu \mathrm{l} 10 \mathrm{mM}$ dNTP Mix, $500 \mathrm{ng}$ total RNA and distilled water with a total volume of $12 \mu \mathrm{l}$ were added to a nuclease-free microcentrifuge tube. The tubes were heated to $65^{\circ} \mathrm{C}$ for 5 minutes and quickly cooled on ice. After adding $4 \mu \mathrm{l} 5 \mathrm{X}$ First-Strand Buffer, $2 \mu \mathrm{l} 0.1$ M DTT, $1 \mu \mathrm{l}$ RNaseOUT ${ }^{\mathrm{TM}}$ and $1 \mu \mathrm{l}$ (200 units) of M-MLV RT (Invitrogen Life Technologies, Carlsbad, CA, USA) to each tube, the tubes were incubated for 50 minutes. The reaction was ended by heating at $70^{\circ} \mathrm{C}$ for 15 minutes.

\section{Quantitative real-time Polymerase Chain Reaction (PCR)}

Real-time PCR reaction was carried out using the Roche Light Cycler and utilizing Roche SYBR Green reagents (Roche, Basel, Switzerland) according to manufacturer's instruction. Each sample contained $2.5 \mathrm{mM} \mathrm{MgCl}_{2}$, $0.2 \mu \mathrm{M}$ of each forward and backward primer, $1 \mu \mathrm{l}$ DNA master SYBR Green, and $1 \mu \mathrm{l}$ cDNA. The reaction was carried out with 1 cycle at $95^{\circ} \mathrm{C}$ for 10 minutes, followed by 40 cycles with a denaturing phase at $95^{\circ} \mathrm{C}$ for 15 seconds, an annealing phase of 5 seconds at $60^{\circ} \mathrm{C}$ and an elongation phase at $72^{\circ} \mathrm{C}$ for 15 seconds. Melting curve analysis was done to verify the accuracy of the amplification before reading the result. The sequences of specific primers used in this study were summarized in Table 1. LY-294002 (Sigma-Aldrich Co.), a specific PI3K inhibitor, was used to evaluate the role of PI3K pathway in downstream signaling of estradiol.

\section{Western blot}

To evaluate the protein expression of p-JNK, p-ERK, p-p38, and MMP-13 under the influence of estradiol, LF cells in different experimental groups were incubated for 72 hours before western blotting analysis. Antibodies specific to the p-JNK, p-ERK, p-p38, and actin were purchased from Cell Signaling Technology, Inc. Antibodies specific to MMP-13 was purchased from Abcam, plc. LF cells were then lysed and centrifuged at $14,000 \mathrm{~g}$ for $10 \mathrm{~min}$ at $4^{\circ} \mathrm{C}$. Equal 
Table 1 Forward and reverse primers and probes used for RT-PCR analysis

\begin{tabular}{ll}
\hline Gene & Primer/Probe Sequences \\
\hline GADPH & 5'-TTCATTGACCTCAACTACAT-3' \\
& 5'-GAGGGGCCATCCACAGTCTT-3' \\
Type I collagen & 5'-CAGACCAACAACCCAAACTCAAT-3' \\
& 5'-TGCACTITGGTITTGGTCAC-3' \\
Elastin & 5'-CCGCTAAGGCAGCCAAGTATGGA-3' \\
& 5'-AGCTCCAACCCCGTAAGTAGGAAT-3' \\
MMP-1 & 5'-CGGTTITCAAAGGGAATAAGTACT-3' \\
& 5'-TCAGAAAGAGCAGCATCGATATG-3' \\
MMP-2 & 5'-TGAGCTCCCGGAAAAGATTG-3' \\
& 5'-GGTGCTGGCTGAGTAGATCCA-3' \\
MMP-9 & 5'-CCTGGAGACCTGAGAACCAATC-3' \\
& 5'-TTCGACTCTCCACGCATCTCT-3' \\
MMP-13 & 5'-ACAGTTGATAGACTCCGAGAAATGC-3' \\
& 5'-ACCATTTGAGTGTCGAGGGA-3' \\
\hline
\end{tabular}

amounts of proteins were separated by SDS-PAGE on $10 \%$ gel and then transferred to nitrocellulose membrane, followed by blocking with $5 \%$ bovine serum albumin (BSA) for $1 \mathrm{~h}$ at room temperature. The membrane was then incubated overnight at $4^{\circ} \mathrm{C}$ with rabbit monoclonal antibody specific to the p-JNK, p-ERK, p-p38(1:1000), or MMP-13(1:400). After three washes, the membrane was incubated with anti-rabbit IgG conjugated with horseradish peroxidase (HRP) for $1 \mathrm{~h}$ at room temperature. Detection was performed with luminal chemiluminescent systems. Quantitative data were obtained using a computing densitometer and Multi Gauge software version 3.0 (Fuji Photo Film Co., Ltd, Tokyo, Japan). ICI 182780 (Sigma-Aldrich Co.), an estrogen receptor antagonist, was used for the blocking of estradiol effect in experimental groups.

\section{Statistical analysis}

All data were expressed as mean \pm standard error of the mean (SEM). Comparison between the experimental groups and the control group were measured using Student's t test. Non-parametric one sample Wilcoxon test was used for the analysis of RT-PCR results. The level of statistic significance was defined as $p<0.05$.

\section{Results}

Estrogen receptors were found on both female and male ligamentum flavum

Immunohistochemistry revealed estrogen receptor- $\beta$ was positively stained in both male and female LF cells with similar density, while estrogen receptor- $\alpha$ was identified on female LF cells with lower density and was barely seen on cells from a male patient (Figure 1).
Low dose estradiol increased proliferation at early culture of LF cells

$17 \beta$-estradiol at a concentration of $10^{-8} \mathrm{M}, 10^{-9} \mathrm{M}$, or $10^{-10} \mathrm{M}$ significantly increased proliferation of ligamentum flavum cells at 24 hours but not at Day 3 or Day 7 of culture (Figure 2A, 2B, 2C). The influence of $17 \beta$-estradiol on cell proliferation at 24 hours was inversely related to the concentration (Figure 2A). $17 \beta$-estradiol of $10^{-7} \mathrm{M}$ did not influence cell proliferation at any experimental time point (Figure 2A, 2B, 2C).

\section{Estradiol decreased soluble collagen in the cultured medium of LF cells but not at the transcription level} Measurement of soluble collagen and elastin in the medium of cell culture ten days after the treatment of $17 \beta$-estradiol $\left(10^{-7}-10^{-9} \mathrm{M}\right)$ using Sirocol collagen assay and FASTIN elastin assay respectively revealed significant decrease in collagen concentration (Figure $3 \mathrm{~A}$ ). The baseline amount of soluble elastin was low as compared to collagen level in the culture medium. Estradiol did not decrease the amount of elastin significantly at Day 10 (Figure 3B). However, the results showed estradiol treatment significantly lowered the collagen to elastin ratio at day 10 (Figure $3 \mathrm{C}$ ). We also examined the influence of $17 \beta$-estradiol $\left(10^{-7}-10^{-9} \mathrm{M}\right)$ on collagen and elastin mRNA expression after 24 hours of treatment, but mRNA expression of collagen did not yield significant change (Figure 3D, 3E). Under high concentration of $17 \beta$-estradiol $\left(10^{-7} \mathrm{M}\right)$ treatment, the mRNA expression of elastin increased.

Estradiol increased the expression of collagenase MMP-13 The matrix-degrading enzymes, matrix metalloprotienases (MMPs), are a family of zinc-dependent endopeptidases capable of degrading the components of the extracellular matrix [21-23]. Specific MMPs had been noticed to be overly expressed in human ligamentum flavum [24]. We examined two collagenases (MMP-1 and MMP-13) and two gelatinases (MMP-2 and MMP-9) in human LF cell culture under the treatment of $17 \beta$-estradiol $\left(10^{-7}-10^{-9} \mathrm{M}\right)$ at 24 hours. Estradiol significantly up-regulated the expression of MMP-13 mRNA. The expression of MMP-13 mRNA increased 2.5 times especially with low dose $\left(10^{-9} \mathrm{M}\right) 17 \beta$-estradiol (Figure $\left.4 \mathrm{~A}\right)$. However, estradiol did not significantly influence MMP-1, MMP-2, and MMP-9 mRNA expression (data not shown).

\section{Estrogen receptor antagonist could reverse the up-} regulation of MMP-13 expression level and protein level caused by estradiol

We measured the expression of MMP-13 at mRNA and protein levels (secreted in culture medium) under the treatment of $10^{-9} \mathrm{M} 17 \beta$-estradiol with or without an estrogen receptor antagonist, ICI $182780\left(10^{-7} \mathrm{M}\right)$. We 


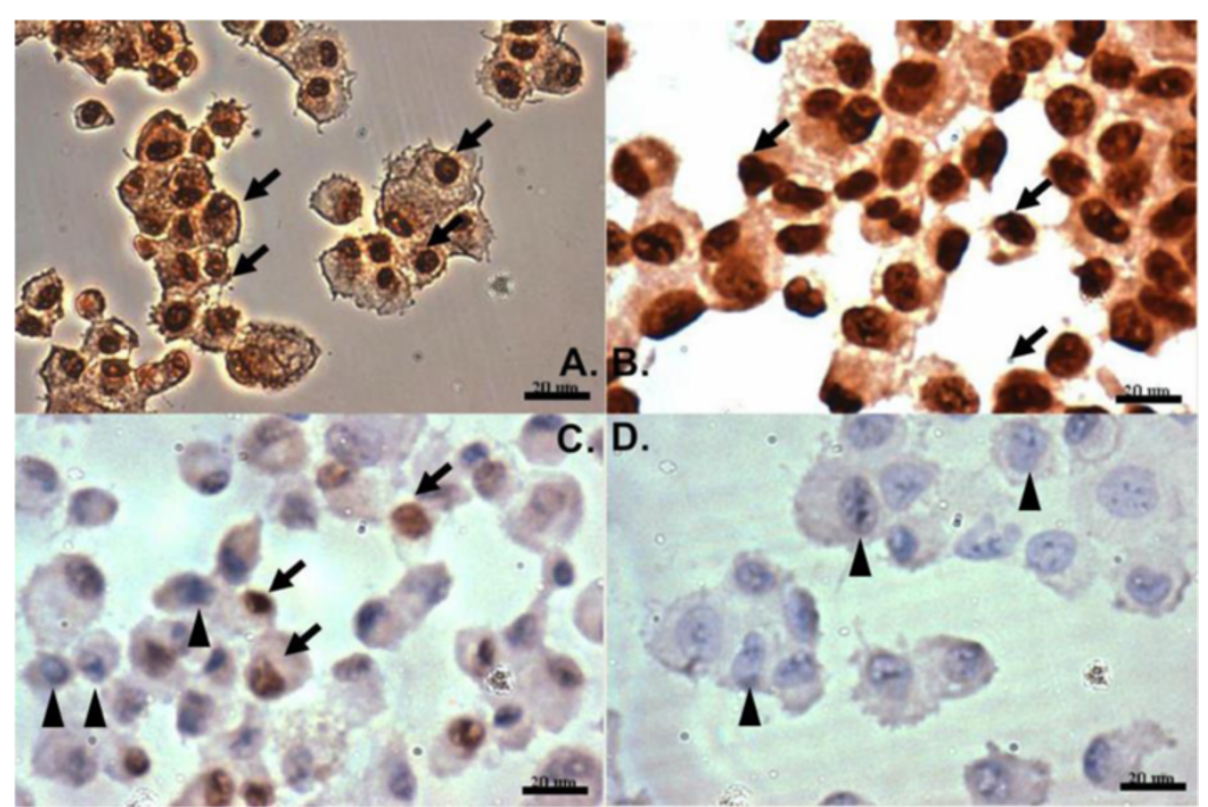

Figure 1 Staining for estrogen receptors of LF cells. (A) and (C) showed ligamentum flavum cells taken from a female patient. (B) and (D) showed ligamentum flavum cells taken from a male patient. In (A) and (B), cells were stained for estrogen receptor $\beta$. In (C) and (D), cells were stained for estrogen receptor $a$. Positively stained cell are brown in color (arrow). Some cells in (C) and most of the cells in (D) were not stained by antibodies showing blue in color (arrow heads).

found that up-regulation of expression of MMP-13 could be attenuated at both mRNA and protein levels by blocking the estrogen receptors with ICI 182780 (Figure $4 \mathrm{~B}$ and $4 \mathrm{C}$ ).

Regulation of MMP-13 by estradiol might not be related to mitogen-activated protein kinase (MAPK/ERK) pathway Downstream signaling of estrogen receptors may involve MAPK pathway or phosphoinositide 3-kinase (Pl3K/AKT) pathway [25]. We analyzed downstream molecules of MAPK pathway including p-ERK, p-JNK, and p-p38 by Western blotting 6 hours and 24 hours after LF cells treated with $10^{-9} \mathrm{M} 17 \beta$-estradiol. No significant change was noted while compared to the control group (Figure 5A and 5B).

\section{Up-regulation of MMP-13 expression by estradiol could be attenuated by blocking PI3K pathway}

Another downstream signaling pathway of estrogen receptor, PI3K, was also investigated by quantitative realtime PCR. MMP-13 mRNA expression stimulated by $10^{-}$

$9 \mathrm{M} 17 \beta$-estradiol at 24 hours could be attenuated by adding LY-294002, an inhibitor of PI3K (Figure 5C).

\section{Discussion}

Hypertrophy of ligamentum flavum contributes to the development of lumbar spinal stenosis, which is one of the most common spinal disorders in the elderly patients and frequently causes neurogenic claudication, functional limitation and immobilization [1,26]. As menopause has great influences on osteoporosis and other connective tissue disorder, it will not be surprising if estradiol plays a role in the regulation of collagen metabolism of the ligamentum flavum and contributes to the pathophysiological mechanisms of lumbar stenosis. Studying LF cells can be difficult because the degenerative yellow ligament in elderly has relatively low density of cells. Therefore, we collected and grew cells from the ligamentum flavum before immunohistochemical studies. We found estrogen receptor- $\beta$ presented on LF cells with similar density in both male and female patients, while estrogen receptor- $\alpha$ was barely seen in LF cells in male (Figure 1). The gender difference in the distribution of estrogen receptor- $\alpha$ in LF cells was similar to that in rat cardiomyocytes in another study [27]. The estrogen- $\alpha$ and estrogen- $\beta$ receptors can form heterodimer to initiate transcription [28] and demonstrate significant differences in their response to anti-estradiols [29]. Those special regulatory mechanisms explain the complex nature of estradiol's effects. Although we found the distribution of receptor- $\alpha$ varied with different genders, we still had to pool the LF cells from both genders to investigate estradiol's effects on LF cells due to limited sources of samples. We evaluated the effects of estradiol of different concentrations $\left(10^{-7} \mathrm{M}, 10^{-8} \mathrm{M}, 10^{-9} \mathrm{M}\right.$, and $\left.10^{-10} \mathrm{M}\right)$ on the proliferation of cultured LF cells at 24 hours, day 3 and day 7. The physiological range of serum estradiol in non-pregnant women can be very wide. The highest concentration of serum estradiol is about $10^{-9} \mathrm{M}$ at preovulatory peak in 

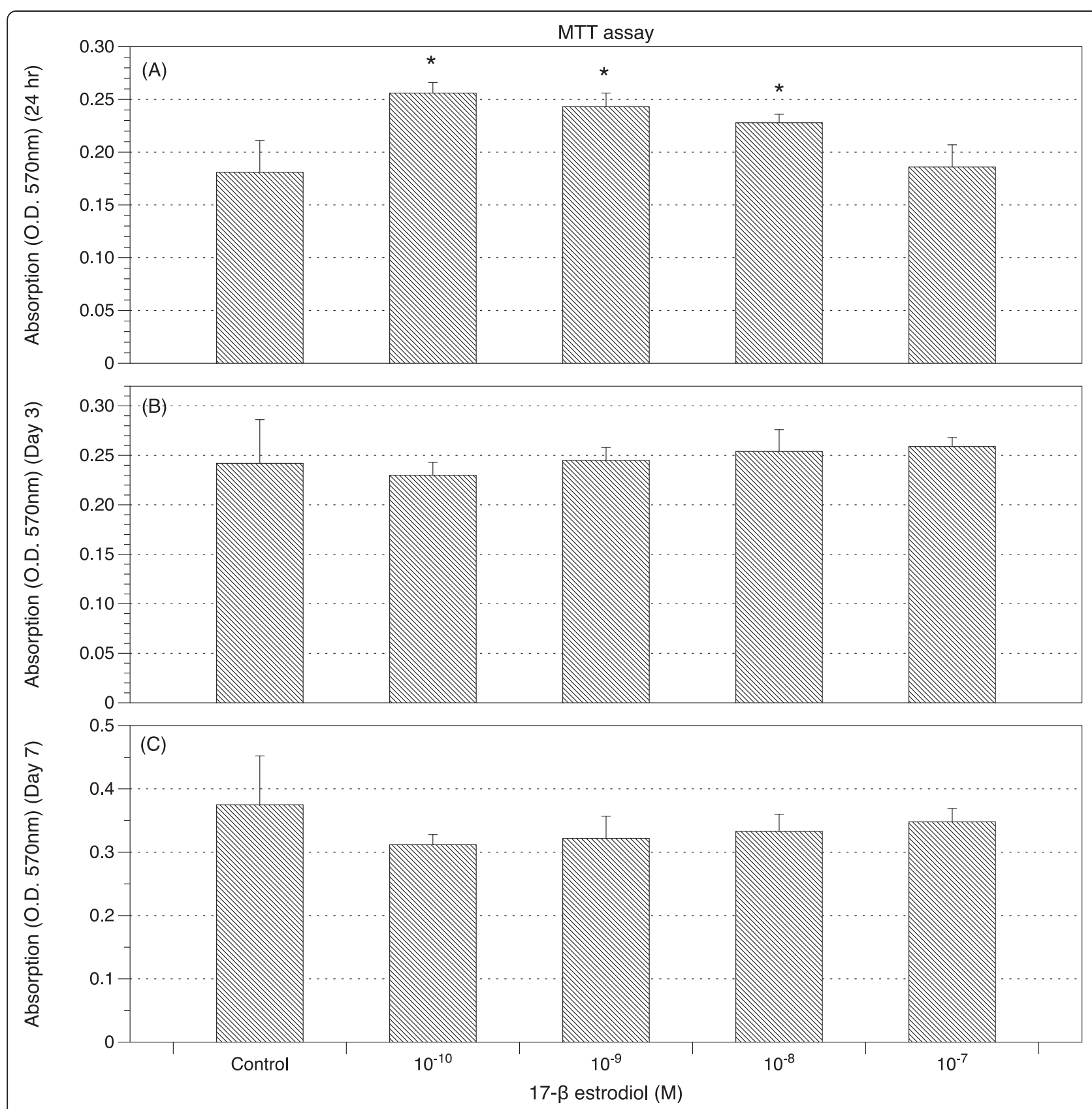

Figure 2 Effects of estradiol on proliferation of LF cells by MTT assay. Proliferation of ligamentum flavum cells was measured by MTT assay at 24 hours (A), Day 3 (B) and Day 7 (C) treated with $17 \beta$-estradiol $\left(10^{-7}>\mathrm{M}, 10^{-8} \mathrm{M}, 10^{-9} \mathrm{M}\right.$, and $\left.10^{-10} \mathrm{M}\right)$. The level of proliferation was presented as optical density (O.D.) of absorbance at $570 \mathrm{~nm}$. $\left(n=6 ;^{*} p<0.05\right)$.

adult female. The concentration is around $10^{-10} \mathrm{M}$ or even lower in post-menopausal women. We found $10^{-7} \mathrm{M}$ $17 \beta$-estradiol did not influence cell proliferation at any time point during the experiments. However, in the early stage (24 hours), $17 \beta$-estradiol with a concentration of $10^{-8} \mathrm{M}, 10^{-9} \mathrm{M}$, or $10^{-10} \mathrm{M}$ significantly increased the proliferation of LF cells in an inversely dose-dependent manner (Figure 2). Our results implied that a concentration of $17 \beta$-estradiol $\left(10^{-7} \mathrm{M}\right)$ above physiological range might prevent the proliferation of LF cells. While the density of cultured cells increased (O.D. $>0.25$ by MTT assay) or the cells matured (cultured more than 3 days), proliferation of LF cells became more resistant to the stimulation from $17 \beta$-estradiol of low concentration $\left(10^{-8} \mathrm{M}, 10^{-9} \mathrm{M}\right.$, or $\left.10^{-10} \mathrm{M}\right)$.

In addition to the proliferation of LF cells, metabolism of extracellular matrix in ligamentum flavum may also play an important role in lumbar spinal stenosis. Change 


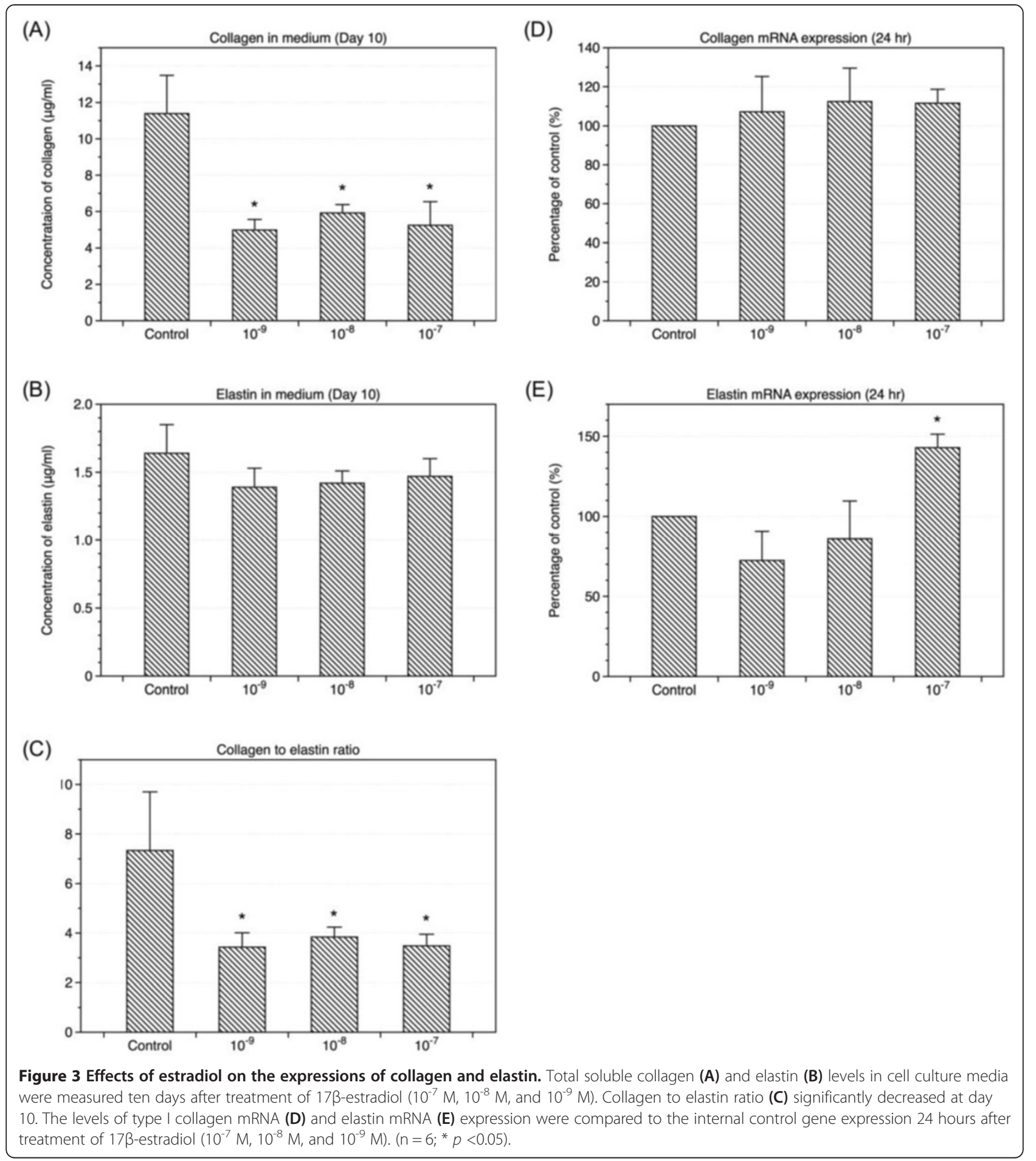

of the ratio of elastin to collagen has been considered as a sign of developing lumbar spinal stenosis in elder patients [10]. We measured the soluble elastin and collagen in the culture medium at Day 10 after the treatment of $17 \beta$-estradiol $\left(10^{-7} \mathrm{M}, 10^{-8} \mathrm{M}, 10^{-9} \mathrm{M}\right)$ using FASTIN and Sirocol assays respectively. We found soluble collagen was reduced after administration of $17 \beta$-estradiol
(Figure 3A). Interestingly, collagen to elastin ratio decreased after LF cells were treated with $17 \beta$-estradiol (Figure $3 \mathrm{C}$ ). The results might indicate that the deficiency of estradiol in elderly contributes to the aging processes of the ligamentum flavum. In postmenopausal women, hormone replacement therapy has benefit for skin because estradiol may increase collagen and other extracellular 

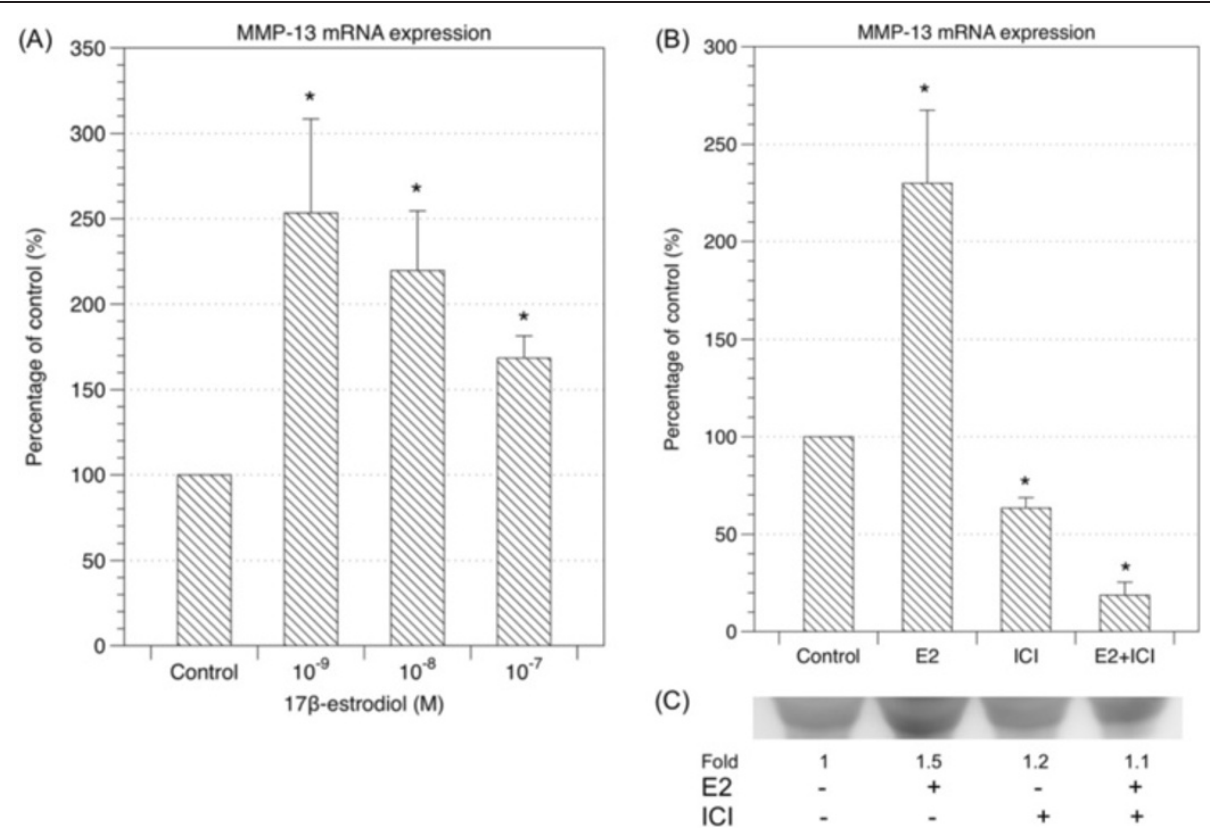

Figure 4 Estradiol regulated the expressions of matrix metalloproteinases. (A) Estradiol significantly increased the expression of MMP-13 at 24 hours (* $p<0.05$ ), but not those of MMP-1, MMP-2, and MMP-9 (not shown). (B) \& (C) Up-regulation of expression of MMP-13 mRNA (B) and protein (secreted in culture medium) $\mathbf{( C )}$ by $10^{-9} \mathrm{M} 17 \beta$-estradiol could be attenuated by estrogen receptor antagonist $\left(10^{-7} \mathrm{M} \mathrm{ICI} \mathrm{182780)}\right.$. $(\mathrm{n}=6$; * $p<0.05)$ (E2: 17ß-estradiol; ICl: ICl 182780).

matrix. It was surprising that treatment with $17 \beta$-estradiol decreased soluble collagen in the culture medium of LF cells. However, the yellow ligament is named for its richness of elastin and the suppression of collagen in its growing stage might have association with the high elastin content in this special tissue. Since estradiol did not alter mRNA expression of collagen (Figure 3D), the reduction of collagen might be due to its degradation. The matrixdegrading enzymes, matrix metalloprotienases (MMPs), are a family of zinc-dependent endopeptidases capable of degrading the components of the extracellular matrix [21-23]. Specific MMPs had been noticed to be overly expressed in human ligamentum flavum [24]. In this study, we examined the expression of MMP-1,

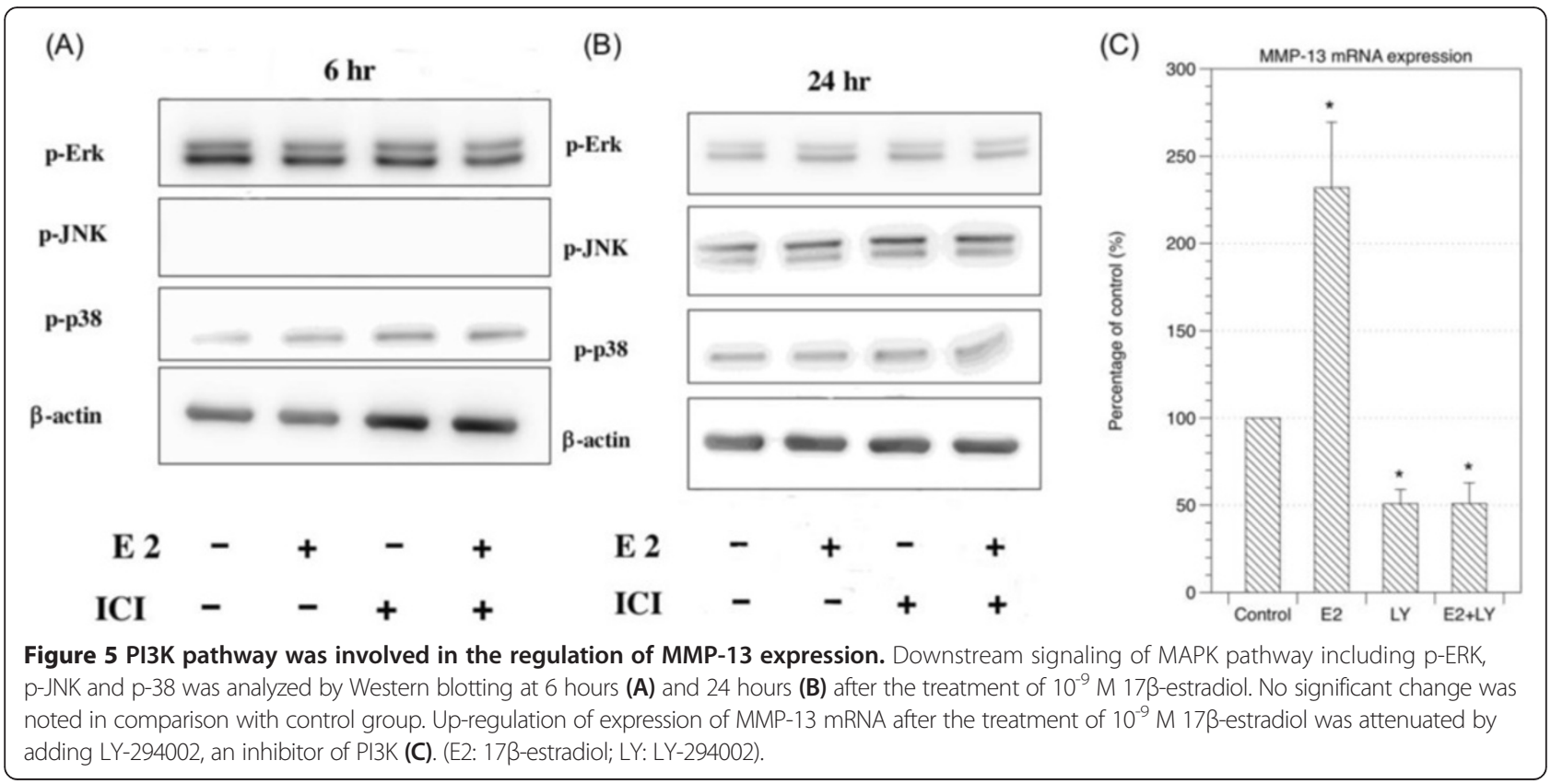


MMP-2, MMP-9, and MMP-13 in LF cells treated with $17 \beta$-estradiol $\left(10^{-7}-10^{-9} \mathrm{M}\right)$ at 24 hours. $17 \beta$-estradiol significantly up-regulated the expression of MMP-13 mRNA to 2.5 times at the concentration of $10^{-9} \mathrm{M}$. Nonetheless, the expression of MMP-13 caused by $17 \beta$-estradiol could be suppressed with an estrogen receptor antagonist (ICI 182780) (Figure 4B and 4C). This confirmed the expression of MMP-13 could be resulted from the activation of estrogen receptors. Activation of estrogen receptors will send signals to the nucleus through the mitogen-activated protein kinase (MAPK/ERK) pathway or phosphoinositide 3-kinase (Pl3K/AKT) pathway [25]. Yet, the downstream proteins of MAPK pathway evaluated by western blot did not show significant change 6 and 24 hours after the treatment of $17 \beta$-estradiol $\left(10^{-9} \mathrm{M}\right)$ with and without estrogen receptor antagonist (ICI 182780) (Figure 5A and 5B). On the other hand, adding an inhibitor of PI3K pathway could suppress the expression of MMP-13 stimulated by $17 \beta$-estradiol (Figure $5 \mathrm{C}$ ). As a result, we believed that $10^{-9} \mathrm{M} 17 \beta$-estradiol regulated the expression of MMP-13 via the PI3K downstream signaling and, in turn, played a role in the collagen metabolism. Park et al also reported the increased expression of MMP-13 by the ligamentum flavum fibroblasts in patients with lumbar stenosis [24]. However, other studies suggested the expression of tissue inhibitors of metalloproteinases (TIMPs) increased in the hypertrophic ligamentum flavum [30]. On the basis of our study and those previous findings, it is difficult to simply conclude a specific role of estradiol at low concentration $\left(10^{-9} \mathrm{M}\right)$ in the pathophysiological mechanism of ligamentum flavum hypertrophy. However, a possible explanation is that $17 \beta$-estradiol at a concentration of $10^{-9} \mathrm{M}$ may contribute to the degradation of extracellular matrix components via the PI3K pathway. The catabolic extracellular matrix products may consequently stimulate the expression of TIMPs in vivo. Furthermore, change in the ratio of elastin to collagen then contributes to the development of degenerative hypertrophic change of the ligamentum flavum. Thus, deficiency of estradiol in menopausal female might alter the homeostasis of extracellular matrix and play a role in the development of lumbar stenosis. Nonetheless, further understanding and studies on the physiological changes of estradiol concentration during different stages of aging, expression levels of MMPs and TIMPs for the various degrees of elastin degradation, fibrosis, and hypertrophy of the ligamentum flavum are necessary to define the exact relationship between estradiol and hypertrophy of ligamentum flavum.

\section{Conclusion}

The association between estradiol and the ligamentum hypertrophy was seldom explored before. In this study, we revealed that estradiol increased early proliferation of LF cells in a dose dependent manner. Estradiol could decrease collagen levels, lower collagen to elastin ratio, and increase MMP-13 through PI3K pathway. From these findings, we suggested that estradiol could play a role in regulating the development of lumbar spinal stenosis through the alterations of both cell viability and matrix metabolism of the ligamentum flavum.

\section{Abbreviations}

MMP: Matrix metalloproteinase; PI3K: Phosphoinositide 3-kinase;

LF: Ligamentum flavum; TGF- $\beta$ : Transforming growth factor beta; PBS: Phosphate-buffered saline; DMEM: Dulbecco's modified eagle medium; FBS: Fetal bovine serum; MTT: 3-[4,5-dimethylthiazol]-2,5-diphenylterazolium bromide; DMSO: Dimethylsulfoxide; RNA: Ribonucleic acid; PCR: Polymerase chain reaction; HRP: Horseradish peroxidase; MAPK: Mitogen-activated protein kinase; TIMP: Tissue inhibitors of metalloproteinase.

\section{Competing interests}

The authors declared that they did not receive any honoraria or consultancy fees in writing this manuscript. No benefits in any form have been received or will be received from a commercial party related directly or indirectly to the subject of this article. All authors declare no conflict of interest.

\section{Authors' contributions}

MeHsC, JSS, PRC, MiHoC contributed to the design and conception of the study. CKH, YSC contributed to the collection of human specimens and acquisition of data. MeHsC wrote the paper. MiHoC contributed to the analysis of data, critical revision of the manuscript. All authors read and approved the final manuscript.

\section{Acknowledgments}

Support for this research was provided through National Taiwan University Hospital Hsin-Chu Branch from Grants HCH 101-19.

\section{Author details}

'Department of Internal Medicine, Far Eastern Memorial Hospital, Taipei, Taiwan. ${ }^{2}$ Department of Surgery, Mackay Memorial Hospital, Taipei, Taiwan. ${ }^{3}$ Department of Biological Science and Technology, National Chiao-Tung University, Hsin-Chu City, Taiwan. ${ }^{4}$ Department of Biomedical Engineering, Ming Chuan University, Taoyuan, Taiwan. ${ }^{5}$ Department of Biomedical Engineering, National Yang-Ming University, Taipei, Taiwan. ${ }^{6}$ Department of Orthopedics, National Taiwan University Hospital Hsin-Chu Branch, Hsin-Chu City, Taiwan. ${ }^{7}$ Department of Surgery, National Taiwan University Hospital Hsin-Chu Branch, Hsin-Chu City, Taiwan.

Received: 22 January 2014 Accepted: 9 July 2014

Published: 15 July 2014

\section{References}

1. Siebert E, Prüss H, Klingebiel R, Failli V, Einhäupl KM, Schwab JM: Lumbar spinal stenosis: syndrome, diagnostics and treatment. Nat Rev Neurol 2009, 5:392-403.

2. Kirkaldy-Willis WH, Paine KW, Cauchoix J, Mclvor G: Lumbar spinal stenosis. Clin Orthop Relat Res 1974, 99:30-50.

3. Shafaq N, Suzuki A, Terai H, Wakitani S, Nakamura H: Cellularity and cartilage matrix increased in hypertrophied ligamentum flavum: histopathological analysis focusing on the mechanical stress and bone morphogenetic protein signaling. J Spinal Disord Tech 2012, 25:107-115.

4. Ishimoto $Y$, Yoshimura N, Muraki S, Yamada H, Nagata K, Hashizume H, Takiguchi N, Minamide A, Oka H, Kawaguchi H, Nakamura K, Akune T, Yoshida M: Prevalence of symptomatic lumbar spinal stenosis and its association with physical performance in a population-based cohort in Japan: the Wakayama spine study. Osteoarthr Cartil 2012, 20:1103-1108.

5. Matveeva N, Vrchakovski M: Lumbar Spinal Stenosis in Older Adults-Gender Differences. Maced J Med Sci 2009, 2:200-204.

6. Miyakoshi N, Itoi E, Murai H, Wakabayashi I, Ito H, Minato T: Inverse relation between osteoporosis and spondylosis in postmenopausal women as 
evaluated by bone mineral density and semiquantitative scoring of spinal degeneration. Spine 2003, 28:492-495.

7. Evans $\mathrm{JH}$, Nachemson AL: Biomechanical study of human lumbar ligamentum flavum. J Anat 1969, 105:188-189.

8. Yahia LH, Garzon S, Strykowski H, Rivard CH: Ultrastructure of the human interspinous ligament and ligamentum flavum: a preliminary study. Spine 1990, 15:262-268.

9. Sairyo K, Biyani A, Goel V, Leaman D, Booth R, Thomas J, Gehling D, Vishnubhotla L, Long R, Ebraheim N: Pathomechanism of ligamentum flavum hypertrophy: a multidisciplinary investigation based on clinical, biomechanical, histologic, and biologic assessments. Spine 2005, 30:2649-2656

10. Kosaka H, Sairyo K, Biyani A, Leaman D, Yeasting R, Higashino K, Sakai T, Katoh S, Sano T, Goel VK, Yasui N: Pathomechanism of loss of elasticity and hypertrophy of lumbar ligamentum flavum in elderly patients with lumbar spinal canal stenosis. Spine 2007, 32:2805-2811.

11. Brincat MP, Calleja-Agius J, Baron YM: The skin, carotid and intervertebral disc: making the connection! Climacteric 2007, 10(Suppl 2):83-87.

12. Calleja-Agius J, Muscat-Baron Y, Brincat MP: Estrogens and the intervertebral disc. Menopause Int 2009, 15:127-130.

13. Hall G, Phillips TJ: Estrogen and skin: the effects of estrogen, menopause, and hormone replacement therapy on the skin. J Am Acad Dermatol 2005, 53:555-568. quiz 569-72.

14. Irie T, Takahata M, Majima T, Abe Y, Komatsu M, Iwasaki N, Minami A: Effect of selective estrogen receptor modulator/raloxifene analogue on proliferation and collagen metabolism of tendon fibroblast. Connect Tissue Res 2010, 51:179-187.

15. Nakada T, Kubota Y, Sasagawa I, Suzuki H, Watanabe M, Suzuki Y: The effect of oestradiol-17 beta on connective tissue protein in rat prostate. Int Urol Nephrol 1994, 26:327-335.

16. Natoli AK, Medley TL, Ahimastos AA, Drew BG, Thearle DJ, Dilley RJ, Kingwell BA: Sex steroids modulate human aortic smooth muscle cell matrix protein deposition and matrix metalloproteinase expression. Hypertension 2005, 46:1129-1134.

17. Son ED, Lee JY, Lee S, Kim MS, Lee BG, Chang IS, Chung JH: Topical application of 17beta-estradiol increases extracellular matrix protein synthesis by stimulating tgf-beta signaling in aged human skin in vivo. J Invest Dermatol 2005, 124:1149-1161.

18. Sanada H, Shikata J, Hamamoto H, Ueba Y, Yamamuro T, Takeda T: Changes in collagen cross-linking and lysyl oxidase by estrogen. Biochim Biophys Acta 1978, 541:408-413.

19. Lin G, Ning H, Wang G, Banie L, Lue TF, Lin C-S: Effects of birth trauma and estrogen on urethral elastic fibers and elastin expression. Urology 2010, 76:1018.e8-13.

20. Goupille P, Jayson MI, Valat JP, Freemont AJ: Matrix metalloproteinases: the clue to intervertebral disc degeneration? Spine 1998, 23:1612-1626.

21. Johnson LL, Dyer R, Hupe DJ: Matrix metalloproteinases. Curr Opin Chem Biol 1998, 2:466-471

22. Nagase H, Woessner JF: Matrix metalloproteinases. J Biol Chem 1999, 274:21491-21494.

23. Woessner JF: Matrix metalloproteinases and their inhibitors in connective tissue remodeling. FASEB J 1991, 5:2145-2154

24. Park J-B, Kong C-G, Suhl K-H, Chang E-D, Riew KD: The increased expression of matrix metalloproteinases associated with elastin degradation and fibrosis of the ligamentum flavum in patients with lumbar spinal stenosis. Clin Orthop Surg 2009, 1:81-89.

25. Lorenzo J: A new hypothesis for how sex steroid hormones regulate bone mass. J Clin Invest 2003, 111:1641-1643.

26. Katz JN, Harris MB: Clinical practice. Lumbar spinal stenosis. N Engl J Med 2008, 358:818-825

27. Grohé $\mathrm{C}$, Kahlert S, Löbbert $\mathrm{K}$, Vetter $\mathrm{H}$ : Expression of oestrogen receptor alpha and beta in rat heart: role of local oestrogen synthesis. J Endocrinol 1998, 156:R1-R7.

28. Cowley SM, Hoare S, Mosselman S, Parker MG: Estrogen receptors alpha and beta form heterodimers on DNA. J Biol Chem 1997, 272:19858-19862.
29. Paech K, Webb P, Kuiper GG, Nilsson S, Gustafsson J, Kushner PJ, Scanlan TS: Differential ligand activation of estrogen receptors ERalpha and ERbeta at AP1 sites. Science 1997, 277:1508-1510.

30. Park J, Lee J, Park S, Riew K: Hypertrophy of Ligamentum Flavum in Lumbar Spinal Stenosis Associated with increased proteinase inhibitor concentration. J Bone Joint Surg 2005, 87:2750-2757.

doi:10.1186/1471-2474-15-238

Cite this article as: Chen et al: Dose-dependent regulation of cell proliferation and collagen degradation by estradiol on ligamentum flavum. BMC Musculoskeletal Disorders 2014 15:238.

\section{Submit your next manuscript to BioMed Central and take full advantage of:}

- Convenient online submission

- Thorough peer review

- No space constraints or color figure charges

- Immediate publication on acceptance

- Inclusion in PubMed, CAS, Scopus and Google Scholar

- Research which is freely available for redistribution

Submit your manuscript at www.biomedcentral.com/submit
( BioMed Central 